\title{
THE HALF-MARATHON PARTICIPANTS, WHO ARE THEY AND WHAT MOTIVATES THEM FOR TRAINING AND COMPETITION?
}

\author{
Leif Inge Tjelta, Per Erik Kvåle, Shaher Shalfawi \\ Department of Education and Sports Science, University of Stavanger, Norway
}

\begin{abstract}
The purposes of the present study was to investigate the motives for training and competing among participants in a half-marathon race. A descriptive quantitative research design was developed using a questionnaire to examine the half-marathon runners' interest in running and competition. The total number of participants presented in this study were 862,331 female and 531 male with a mean age $41.8 \pm 10.4$ years. The major reasons for the participants to regularly practice running were because of its importance to their physical and psychological health, because it is fun, and for other health reasons, respectively. Comparing the motives for running between males and females showed that males scored higher on health, losing weight and to be able to measure their running abilities with others. Comparing the main reasons among age groups for participating in half-marathon competition, the majority of the $<40$ years old participated to a greater extent to challenge themselves, to exercise and to experience nature, respectively, compared to $>40$ years old. The results indicate that the major reasons for regularly practice running are that running as activity is important for maintaining physical and physiological health.
\end{abstract}

Keywords: running; physical and psychological health; body weight

\section{INTRODUCTION}

Running has been a central human activity for more than two million years. Primeval man in the early stage of civilization travelled long distances on foot, walking or running [4]. Hunters in different cultures have also been 
reported to run after different prey in a strenuous hunt that could last for one to two days [6]. However, the rise of the farming communities, the arrival of the Industrial Revolution through increased urbanization and the emergence of new means of transport, the importance of being able to move on foot over long distances decreased [17]. Despite the decrease in the necessity to cover long distances on foot in the western world today, there has been an increasing interest in running as a physical activity during the last decades [18].

Classic marathon distance is $42.2 \mathrm{~km}$ with 509,000 participants completed one or more of the more than 480 marathons arranged in the USA only in 2015 [18]. Furthermore, 1,986,600 completed one or more of the 2,700 organized half-marathon $(21.1 \mathrm{~km})$ competitions. This is a substantial increase from 1990 when 224,000 and 303,000 completed marathon and half-marathon competitions, respectively [18]. In Norway, there has also been a substantial increase in the number of participants in half-marathon competitions over the past two decades. The greatest marathon and halfmarathon competition in Norway is Oslo Marathon. In 1981, 1336 competitors finished the half-marathon and 642 the marathon. In 2016, the numbers of participants were 8016 (half-marathon) and 2014 (marathon), respectively [12].

The increased number of participants in half-marathon compared to full marathon is contributed to the extreme demand of the full marathon that requires months of dedicated training [8]. In contrast, half-marathon could be completed by the majority of participants irrespective of their physical activity level, where it has been reported that inactive adults can run a halfmarathon after 12 to 20 weeks of training $[3,7]$.

"Tresjøersløpet" ("The Three Lace Race") was the half-marathon in southwestern Norway with the most participants in 2016. The race was arranged first time in 2006 with 137 participants. In 2016, 2343 completed the race, $37 \%$ were females [1]. Runners who train for and participate in long running competitions have often been asked about their motives for training and participation in races [8]. In 1993, Masters et al. [15] developed a questionnaire; Motivation of Marathoners Scale (MOMS) to identify marathon runners motives for training and competition. This questionnaire and a similar yearly questionnaire "USA National Runner Survey" have provided good insight into the motives marathoners have for running. However, there is surprisingly little data on the motivation of half-marathon runners [8].

Therefore, the purposes of the present study were to investigate the motives of half-marathon runners and further to compare the motives for running in different age groups and between men and women. 


\section{MATERIALS AND METHODS}

\section{Subjects}

The total number of participants presented in this study was 862 with a mean age $41.8 \pm 10.4$ yrs, weight $73.5 \pm 12.5 \mathrm{~kg}$, height $176 \pm 8.9 \mathrm{~cm}$ and BMI $23.6 \pm 2.8 \mathrm{~kg} / \mathrm{m}^{2}$ with a training duration and distance of $3.19 \pm 2.31$ hours and $21.4 \pm 6.0 \mathrm{~km}$ per week, respectively. The training age of the participants was $9.2 \pm 10.7$ years. Among the participants, there were 331 females aged $39.7 \pm 10.5$ yrs, weight $62.7 \pm 8.0 \mathrm{~kg}$, height $168 \pm 6.1 \mathrm{~cm}$, BMI $22.2 \pm 2.6 \mathrm{~kg} / \mathrm{m}^{2}$ with a training duration and distance of $3.19 \pm 1.51$ hours and $20.7 \pm 5.8 \mathrm{~km}$ per week, respectively, with a training age of $8.3 \pm 9.5$ yrs. The number of males was 531 , aged $43.1 \pm 10.1$ yrs, weight $80.3 \pm 9.8 \mathrm{~kg}$, height $181 \pm 6.2 \mathrm{~cm}$, BMI $24.5 \pm 2.6 \mathrm{~kg} / \mathrm{m}^{2}$ with a training duration and distance of $3.18 \pm 2.10$ hours and $21.8 \pm 6.5 \mathrm{~km}$ per week, respectively and a training age of $9.8 \pm 11.3 \mathrm{yrs}$. Participants were further classified according to their age group (Table 1). The study was approved by the Norwegian social science data services.

Table 1. Descriptive statistics of participants

\begin{tabular}{lcccccccc}
\hline $\begin{array}{l}\text { Age } \\
\text { group }\end{array}$ & $\mathbf{N}$ & $\begin{array}{c}\text { Age } \\
(\mathrm{yr} \pm \mathrm{SD})\end{array}$ & $\begin{array}{c}\text { Weight } \\
(\mathrm{kg} \pm \mathrm{SD})\end{array}$ & $\begin{array}{c}\text { Height } \\
(\mathrm{cm} \pm \mathrm{SD})\end{array}$ & $\begin{array}{c}\text { BMI } \\
\left(\mathrm{kg} / \mathrm{m}^{2} \pm \mathrm{SD}\right)\end{array}$ & $\begin{array}{c}\text { Training } \\
(\mathrm{h} / \mathrm{wk} \pm \mathrm{SD})\end{array}$ & $\begin{array}{c}\mathrm{Km} / \\
\mathbf{w k} \pm \mathrm{SD}\end{array}$ & $\begin{array}{c}\text { Training } \\
(\mathrm{age} / \\
\mathbf{y r} \pm \mathrm{SD})\end{array}$ \\
\hline$<20$ & 19 & $17.2 \pm 1.1$ & $61.0 \pm 8.0$ & $171 \pm 8.3$ & $20.7 \pm 1.8$ & $4.37 \pm 2.40$ & $21.6 \pm 6.02$ & $3.2 \pm 2.8$ \\
\hline $20-29$ & 90 & $26.1 \pm 2.3$ & $70.8 \pm 13.9$ & $175 \pm 8.8$ & $23.0 \pm 3.2$ & $3.39 \pm 3.44$ & $21.3 \pm 9.14$ & $4.3 \pm 4.4$ \\
\hline $30-39$ & 230 & $34.8 \pm 2.9$ & $73.0 \pm 13.0$ & $176 \pm 9.3$ & $23.4 \pm 2.8$ & $3.08 \pm 1.48$ & $21.6 \pm 6.58$ & $5.8 \pm 5.7$ \\
\hline $40-49$ & 318 & $44.3 \pm 2.8$ & $75.1 \pm 12.2$ & $176 \pm 9.0$ & $24.0 \pm 2.8$ & $3.02 \pm 1.28$ & $20.8 \pm 5.35$ & $8.8 \pm 9.2$ \\
\hline $50-59$ & 173 & $53.4 \pm 2.8$ & $74.0 \pm 11.7$ & $177 \pm 8.4$ & $23.6 \pm 2.6$ & $3.39 \pm 1.57$ & $21.8 \pm 5.57$ & $14.2 \pm 13.1$ \\
\hline$>60$ & 32 & $64.0 \pm 3.7$ & $74.4 \pm 9.8$ & $177 \pm 5.6$ & $23.7 \pm 2.5$ & $3.43 \pm 1.53$ & $22.2 \pm 6.59$ & $28.9 \pm 18.0$ \\
\hline
\end{tabular}

\section{Procedure}

A descriptive quantitative research design was developed using a questionnaire to examine the participants' interest in running and competition. The questionnaire has a section where participants completed a demographic section, which included age (yrs), weight $(\mathrm{kg})$, height $(\mathrm{cm})$, training duration per week ( $\mathrm{min})$, weekly distance covered $(\mathrm{km})$, and the number of years using running as a form of physical activity. The self-reported height and weight were used to calculate and report BMI. In addition, the questionnaire contained a question to enlighten the reasons to how the participants became interested in running generally with the following answers: "I use 
running to improve myself in a different sport", "to be able to measure my running ability with others", "to reduce my weight", "other health issues", "was influence by friends and family", "I feel like running is important", "cause it is fun", "cause I need new challenge", "important for my physical and psychological health", "just to be able to participate in running venues". Furthermore, questions aimed to enlighten the reasons of participation in a half-marathon competition with the following answers were provided: to "compete", to "exercise", to "experience nature", to "be social" and to "challenge myself". A third and final question was provided to examine to what extent participants use external feedback tools while training such as, heart rate monitors, GPS, music, stopwatch, running apps on smart phone.

After securing a written approval from the organisers of the half marathon competition "Tresjøersløpet", the questionnaire was transformed to a web based survey using SurveyXact version 8.0 [13] that is integrated to the local university server system to insure data security. Then, a link was generated using SurveyXact and distributed to the half-marathon organiser to further distribute it to the participants. Participants who agreed to take part in the study, answered the questionnaire using the link provided in the body of the e-mail message that contained a detailed information about the purpose of the study and how the data will be handled. Furthermore, only participants who were already registered at the "Tresjøersløpet" database were invited to participate and provided with 30 days period to complete the questionnaire. The inclusion criteria were that only participants who completed the questionnaire by answering $100 \%$ of the questions were included for further analyses.

\section{Statistical analysis}

Raw data were transferred to IBM SPSS statistics version 25 for windows and Microsoft Excel 2016 for further analysis. First, the normality of the data was examined using the Shapiro-Wilk and Kolmogorov-Smirnov tests, and the results of the test revealed that all measured variables were not normally distributed. Therefore, Chi-square test was performed to examine differences in scores as a function of sex and age. The statistical significance level was set at $\mathrm{p}<0.05$, and the results were expressed as means and standard deviations. 


\section{RESULTS}

\section{Participating in running as a form of physical activity}

The results indicate that the major reasons for the participants to regularly practice running as a form of physical activity was because of its importance to their physical and psychological health, it is fun, and for other health issues, respectively (Figure 1).

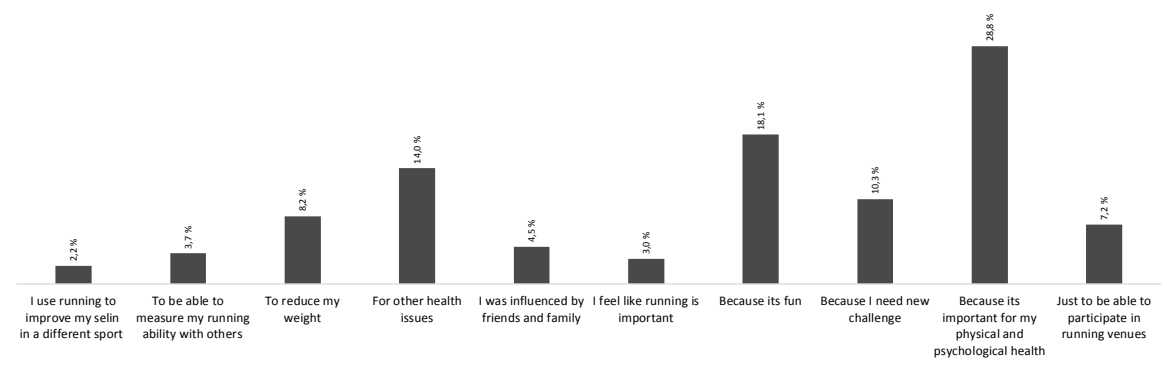

Figure 1. Reasons for practicing running as a form of physical activity.

While the major part of the results indicates the same priority in reasons for participating in running as a form of physical activity, there were a notable $(p<0.05)$ differences between males who scored higher compared to females on health, losing weight and to be able to measure their running abilities with others, respectively (Figure 2). However, the results indicate that the least female prioritise when running was competing with others compared to males who scored lowest on using running to improve in different sport (Figure 2).

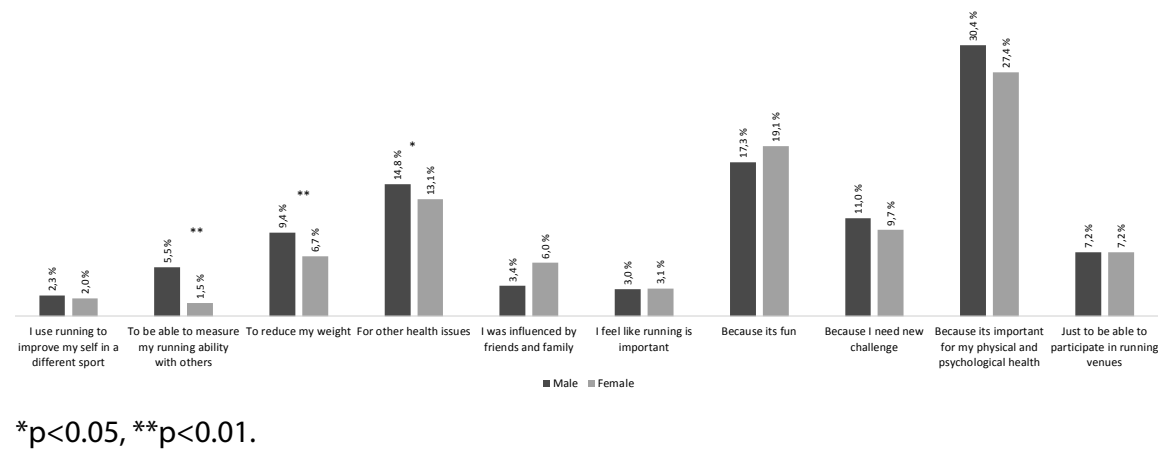

Figure 2. Reasons for practicing running as a form of physical activity among males and females. 
The results indicate that the reasons for participating in running as a form physical activity were different among age groups. It was noticeable $(\mathrm{p}<0.05)$ that participants over $40 \mathrm{yrs}$ old practice running for its importance to their physical and psychological health, health generally and weight reduction, respectively (Figure 3 ), compared to participants younger than 40 yrs old who practice running to be able to measure their running ability with others and to be able to participate in running venues (Figure 3 ). However, the overall priorities of the reasons to practice running seems to be similar in both groups (Figure 3).

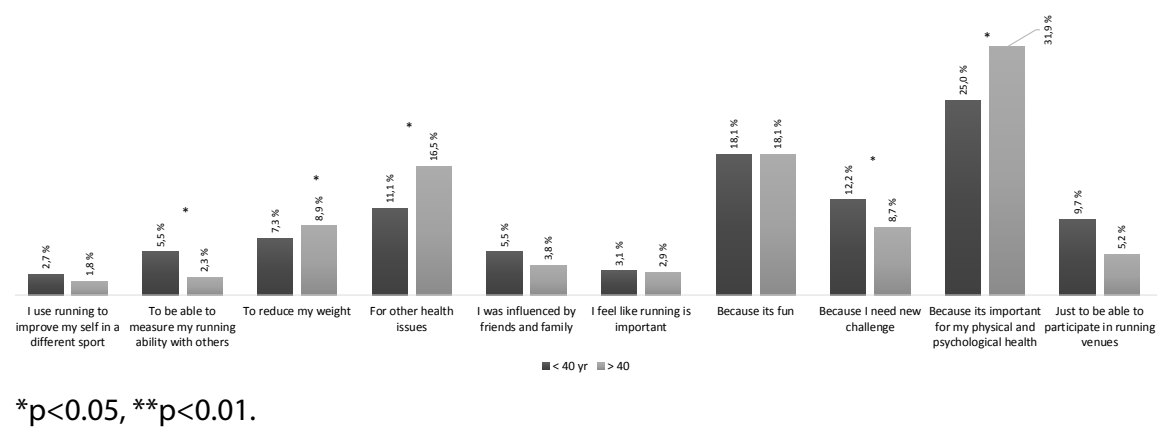

Figure 3. Reasons influencing the participants to practice running as a form of physical activity based on age groups.

\section{Reasons for participating in half-marathon}

The main reasons for male participants to participate in the half-marathon venue were to challenge themselves, to exercise, to compete, to socialise with others and to experience nature, respectively. However, the main reasons for females participation was slightly different, with the main reasons were to challenge themselves, to exercise, to socialise with others, to experience nature and to compete, respectively (Figure 4).

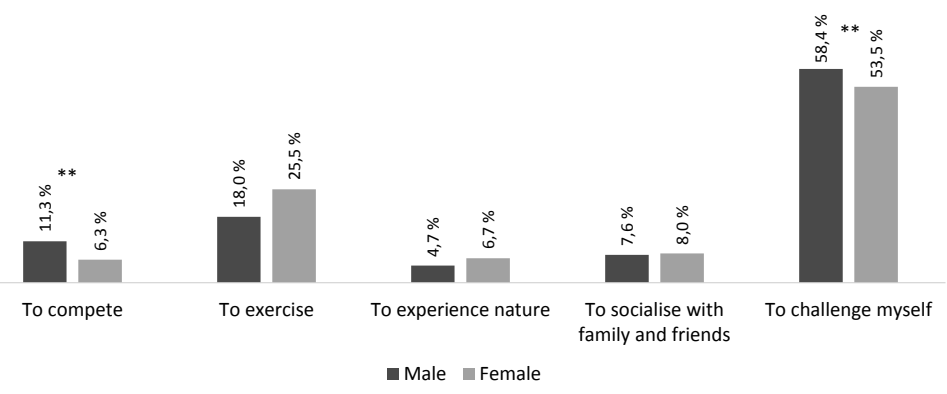

${ }^{*} \mathrm{p}<0.05,{ }^{* *} \mathrm{p}<0.01$.

Figure 4. The major reasons for participating in half marathon as a function of sex. 
Comparing the main reasons for participating in half-marathon among age groups, reveals that the majority $(\mathrm{p}<0.05)$ of the $<40$ yrs old, participate to challenge themselves, to exercise and to experience nature, respectively, compared to $>40$ yrs old (Figure 5).

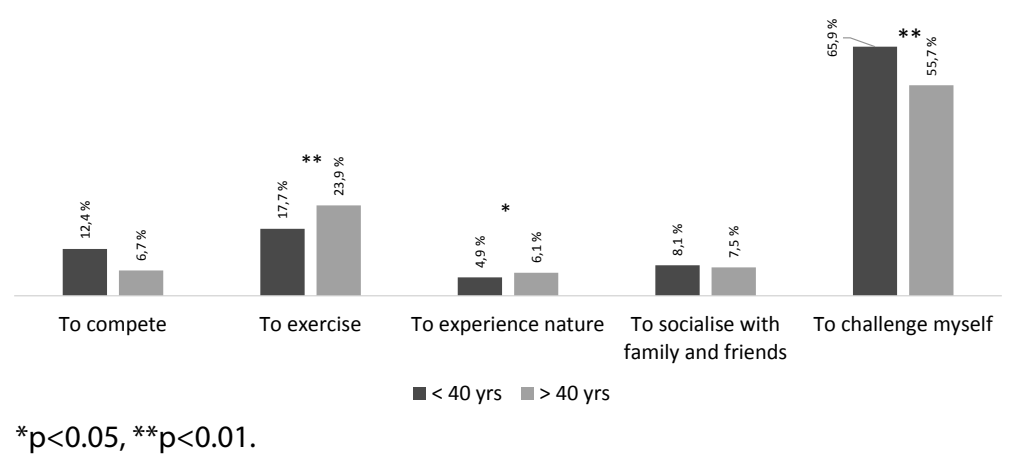

Figure 5. The major reasons for participating in half marathon as a function of age.

\section{Instruments used under training}

The results indicate that males use GPS significantly more than females during training, while females use heart rate monitors without GPS function significantly more than males (Figure 6). Furthermore, males significantly use stopwatch more than females during training (Figure 6). No other differences were observed.

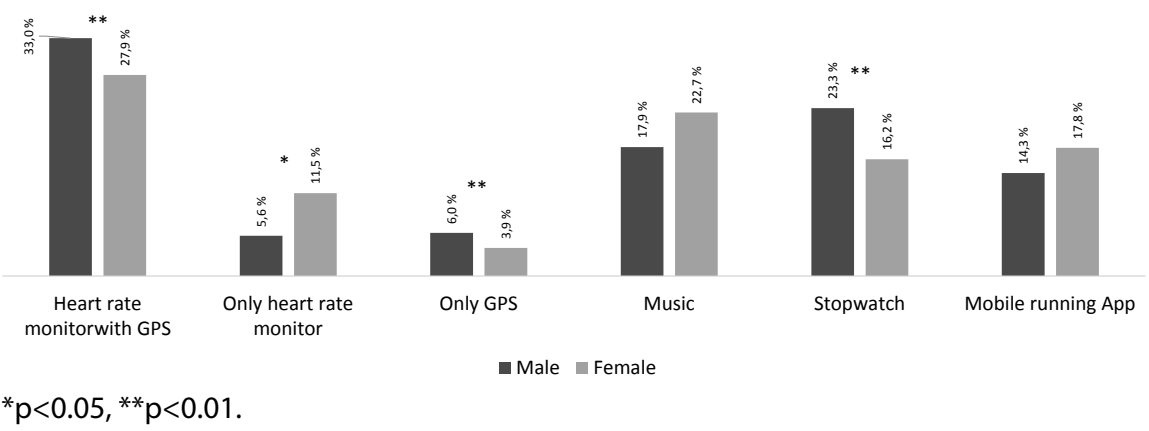

Figure 6. The major tools used during training as a function of sex.

\section{DISCUSSION}

The majority of participants who answered the questionnaire were in age groups $30-39$ and $40-49$, followed by age group $50-59$ (Table 1 ). These age groups have also been found to represent the majority of participants in a half-marathon race in a Sao Paulo, Brazil which in 2009 had 6554 finishers, 
and the growth in number of participants in these age groups was greater than in the other age groups in the period 2003-2009 [19]. The major reasons for the participants to regularly practice running has been reported to be because of it's importance to their physical and psychological health, it is fun, and for other health issues, respectively (Figure 1). These findings are in line with earlier reported results regarding the main reasons for adult Norwegians to participate in physical activities [5]. Furthermore, physiological and psychological wellbeing were also reported to be the most important reasons for practicing running among previous untrained adults who during a 20 weeks training to be able to run a half-marathon race [3].

As motive for practicing running as a form of physical activity, men scored significantly higher compared to women on "be able to measure my running abilities with others" (Figure 2). This is along with an earlier study which also found that men who practised running had stronger competition motive compared to female runners [16]. However, it was notable that males scored higher than females on weight reduction and other health issues (Figure 2). This is in contrast with the study of Ogles et al. [16] who found that women, more than men practiced running for weight control. This can be explained by the latest Norwegian data $[9,10]$ witch says that $75 \%$ of adult males and $60 \%$ of adult females in Norway were found to be classified as overweight or obese. These reports make it logically expected that both males and females, especially males, are concerned in weight reduction activities.

The reasons for participating in running as a physical activity were different between age groups. Younger participants $(<40 \mathrm{yrs})$ were more focused on measuring their running abilities with others compared to older participants ( $\geq 40$ yrs old). Participants over 40 yrs practice running more for their physical and psychological health. These findings are in line with those reported by Allender et al. [2]. This should be considered positive since participation in endurance activities like running can delay age related reduction in aerobic capacity and studies have shown that women and men over 40 yrs can improve their aerobic capacity with training $[3,14,20]$.

There were only small differences between gender regarding reasons to participate in the half-marathon race. To compete and to challenge themselves were the most important reasons for participating in half-marathon competitions for both women and men. However, these motives were significantly more important for men compared to women, which is along with what was reported in an earlier study [16].

In the present study, it was found that male runners used GPS significantly more than females during training (Figure 6). In a similar study of 
runners who participated in the Half-Marathon Eindenhoven 2014 [11] it was, however, found no difference in monitoring devices between gender.

The increase in the number of participants in the half-marathon "Tresjøersløpet" ("The Three Lace Race") from 2006 to 2016 indicates a trend towards engagement in running, using the half-marathon venue as a motivation to practice running as a form of physical activity to improve their physical health generally and physical and physiological health specifically. The majority also indicate using running as a tool for weight control. An explanation for this phenomenon is that running is an activity that can be practised nearly everywhere and that demands little expensive equipment.

\section{REFERENCES}

1. 3sjøersløpet. (2017). http://3sjoers.no/resultater/.

2. Allender S, Cowburn G, Foster C. (2006) Understanding participation in sport and physical activity among children and adults: a review of qualitative studies. Health Educ Res, 21: 826-835.

3. Berge IB, Tjelta LI. (2015) Fra utrent til halvmaratonløper på 20 uker. Fysioterapeuten 8: 16-20.

4. Bramble DM, Lieberman DE. (2004) Endurance running and the evolution of Homo. Nature, 432: 345-352.

5. Breivik G, Vaagbø O. (1998) The development in physical activity in the Norwegian population 1985-1997 (Retrieved from: https://helsedirektoratet.no/ Lists/Publikasjoner/Attachments/728/Fysisk-aktivitet-omfang-tilretteleggingog-sosial-ulikhet-en-oppdatering-og-revisjon-IS-0366.pdf

6. Carrier DR, Kapoor AK, Kimura T, Nickels MK, Satwanti, Scott EC, So JK, Trinkaus E. (1984) The energetic paradox of human running and hominid evolution. Curr Anthropol, 25: 483-495.

7. Dyrstad SM, Tjelta LI. (2013) Newspaper coverage effects on the promotion of a lifestyle intervention program. J Obes, 2013, 516767.

8. Hanson N, Madaras L, Dicke J, Buckworth J. (2015) Motivational differences between half, full and ultramarathoners. J Sport Behav, 38: 180-191.

9. Jacobsen BK, Aars NA. (2015) Changes in body mass index and the prevalence of obesity during 1994-2008: repeated cross-sectional surveys and longitudinal analyses. The Tromsø Study. BMJ Open, 5: e007859.

10. Midthjell K, Lee CM, Langhammer A, Krokstad S, Holmen TL, Hveem K, Colaqiuri S, Holmen J. (2013) Trends in overweight and obesity over 22 years in a large adult population: the HUNT Study, Norway. Clin Obes, 3: 12-20.

11. Janssen M, Scheerder J, Thibaut E, Brombacher A, Vos S. (2017) Who uses running apps and sports watches? Determinants and consumer profiles of event runners' usage of running-related smartphone applications and sports watches. PloS One, 12: e0181167 
12. Kondis (2017) Norwegian association for endurance sports. Participants in half-marathon and marathon races in Norway in 2016.

13. Leadingsystem (2013) SurveyXact. http://www.surveyxact.com/about-us

14. Lexell J, Frändlin K, Helbostad J. (2009) In R. Bahr (Ed.), Aktivitetshåndboken Fysisk aktivitet i forebygging og behandling. Oslo: Helsedirektoratet, pp. 62-71.

15. Masters KS, Ogles BM, Jolton JA. (1993) The development of an instrument to measure Motivation for Marathon running: the Motivations of Marathoners Scales (MOMS). Res Q Exerc Sport, 64: 134-143.

16. Ogles BM, Masters KS, Richardson SA. (1995) Obligatory running and Gender: an analysis of participative motives and training habits. Int J Sport Psychol, 26: 233-248.

17. Popkin BM. (1999) Urbanization, lifestyle changes and nutrition transition. World Dev, 27: 1905-1916.

18. Running USA. (2016). http://www.runningusa.org/annual-reports.

19. Sierra AP, Benetti M, Ghorayeb N, Sierra C, da Cunha Bastos F, Rocco A, Kiss, MAPDM. (2015). Analysis of Participation and Performance in Half Marathon runners. J Sports Sci, 3: 96-104.

20. Tjelta LI, Kvåle OH, Dyrstad SM. (2010) Helseeffekter av sykling til og fra jobb. Tidsskrift for Den norske legeforening, 12: 1246-1249.

\section{Correspondence to:}

Leif Inge Tjelta

Department of Education and Sports Science

University of Stavanger

N-4036 Stavanger, Norway

Tel: +475183 3523

Fax: + 4751833450

E-mail: leif.i.tjelta@uis.no 